\title{
PENGARUH PELUANG PERTUMBUHAN DAN RASIO PENGEMBALIAN AKTIVA TERHADAP PENAHANAN KAS PADA PT. INDOCEMENT TUNGGAL PRAKARSA, TBK.
}

\author{
Syifa Fitria Hanifah \\ Manajemen Keuangan Syariah, UIN Sunan Gunung Djati Bandung \\ syifafitriahan16@gmail.com, \\ Widiawati \\ Manajemen Keuangan Syariah, UIN Sunan Gunung Djati Bandung \\ widiawati@uinsgd.ac.id
}

\begin{abstract}
This research is motivated by the importance of companies to conduct cash holding in order to maintain company liquidity. The availability of cash in the company can be used in operating activities or to pay company obligations. The availability of cash in the company can be relied on by several factors. Therefore, this study aims to analyze the factors that influence cash retention, namely company growth opportunities and company asset ratios. This article also uses descriptive methods and quantitative approaches, namely to describe the research results presented in numerical form. The data in this article is secondary data taken from the financial statements of PT. Indocement Tunggal Prakarsa, Tbk, and supported by a library and documentation studio, which is processed statistically and quantitatively. The results of this study concluded that both partially and simultaneously growth opportunities and asset opportunity ratios do not have a significant effect on cash retention of PT. Indocement Tunggal Prakarsa, Tbk. The contribution of the second variable is only $23.6 \%$, that is, $76.4 \%$ of the retention of cash can be obtained by other factors outside of this study. The implication of this research is that PT. Indocement Tunggal Prakarsa, Tbk. in carrying out cash retention, other factors must be considered because if the available cash is not sufficient it will disrupt the company's operations.
\end{abstract}

Keywords: Growth Opportunity, Return On Assets, Cash Holding.

\begin{abstract}
Abstrak
Penelitian ini dilatarbelakangi oleh pentingnya perusahaan untuk melakukan penahanan kas (cash holding) guna menjaga likuiditas perusahaan. Ketersedian kas pada perusahaan dapat digunakan dalam kegiatan operasi maupun membayar kewajiban perusahaan. Ketersedian kas dalam perusahaan dipengaruhi oleh beberapa faktor. Oleh karena itu, penelitian ini bertujuan menganalisis faktor yang mempengaruhi penahanan kas yaitu peluang pertumbuhan perusahaan dan rasio pengembalian aktiva perusahaan. Artikel ini juga menggunakan metode deskriptif dan pendekatan kuantitatif, yakni untuk mendeskripsikan hasil penelitian yang datanya disajikan dalam bentuk numerik. Data pada artikel ini merupakan data sekunder yang diambil dari laporan keuangan PT. Indocement Tunggal Prakarsa, Tbk dan didukung dengan studi kepustakaan dan dokumentasi, yang diolah secara statistik dan kuantitatif. Hasil penelitian ini menyimpulkan bahwa baik secara parsial dan simultan peluang pertumbuhan dan rasio pengembalian aktiva tidak memiliki pengaruh yang signifikan terhadap penahanan kas PT. Indocement Tunggal Prakarsa, Tbk. Kontribusi kedua variabel hanya 23,6\%, artinya sebesar $76,4 \%$ penahanan kas dipengaruhi oleh faktor-faktor lain diluar penelitian ini. Implikasi dari penelitian ini adalah PT. Indocement Tunggal Prakarsa, Tbk. dalam melakukan penahanan kas harus memperhatikan faktor lain karena jika kas yang tersedia tidak cukup akan mengganggu operasional perusahaan.
\end{abstract}

Kata kunci: Peluang Pertumbuhan, Rasio Pengembalian Aktiva, Penahanan Kas 


\section{Pendahuluan}

Disetiap negara akan selalu terjadi guncangan ekonomi yang menyebabkan krisis finansial baik kategori ringan yang masih bisa diatasi maupun kategori berat. Bagi perusahaan, ketidakstabilan ekonomi akan berdampak pada likuiditasnya, sehingga perusahaan sulit bertahan karena tidak tersedianya dana likuid yang cukup. Pada perusahaan, menjaga likuiditas artinya ketersediaan kas yang mencukupi untuk kegiatan operasional perusahaan dan membayar kewajiban. Selain itu, tersedianya jumlah kas yang memadai dapat menjadi keuntungan bagi perusahaan di masa yang akan datang (Zulhilmi, 2015). Ketersediaan kas juga berguna untuk membiayai kebutuhan sumber daya perusahaan. Oleh sebab itu, perlu dilakukan pengendalian kas yang efektif.

Sebagai salah satu alternatif, para ahli menyebutkan perlunya perusahaan melakukan penahanan kas atau cash holding. Tujuannya tentu untuk meminimalisir risiko yang tidak terduga dan juga mengefisiensikan kas sehingga dapat berputar dengan baik dan tertahan dengan baik pula (Jinkar, 2013). Penahanan kas adalah jumlah kas yang dimiliki oleh perusahaan secara rill yang dapat digunakan untuk penanaman modal baik dalam bentuk aset fisik maupun dibagikan pada investor. Singkatnya, cash holding ini merupakan aktiva perusahaan yang bisa dikonversikan dalam bentuk kas atau uang tunai. Dalam pencatatan akuntansi penahanan kas dikenal dengan cash and equivalent cash (Simanjuntak \& Wahyudi, 2017).

Seperti yang telah dijelaskan di sebelumnya, ketersediaan kas bagi pihak manajemen menjadi salah satu solusi untuk meminimalisir kesulitan keuangan saat terjadi krisis keuangan. Penahanan kas diperoleh dari pembagian antara jumlah kas dan setara kas yang dimiliki perusahaan dengan total aset secara menyeluruh. Penelitian ini mencoba mengetahui faktor yang mempengaruhi PT. Indocement Tunggal Prakarsa menahan kasnya, maka peneliti menduga peluang pertumbuhan atau growth opportunity dan rasio pengembalian aktiva menjadi faktor yang mempengaruhinya.

Peluang pertumbuhan adalah keadaan perusahaan yang digambarkan dalam bentuk rasio sejauh mana perusahaan mampu bertahan dengan posisi ekonominya di tengah pertumbuhan perekonomian perusahaan dan sektor usahanya (Afiyan, 2018). Selain itu peluang pertumbuhan ini merupakan peluang investasi yang mungkin bisa dikembangkan oleh perusahaan. Menurut (Eugene \& Houston, 2006) perusahaan yang mempunyai peluang pertumbuhan yang tinggi harus memiliki kas yang cukup atau penahanan kas yang tinggi agar dapat digunakan dengan cepat dalam menindaklanjuti suatu peluang.

Selanjutnya, rasio pengembalian aktiva yang mencerminkan kinerja perusahaan dalam mengelola aktiva perusahaan yang dimiliki sehingga berdampak pada peningkatan laba. Ketika tingkat pengembalian perusahaan tinggi maka akan berimplikasi pada penggunaan dana eksternal berupa hutang yang rendah dan memungkinkan perusahaan menggunakan dana internalnya dalam membiayai kebutuhan perusahaan. Namun sebaliknya, saat tingkat pengembalian rendah karena kurangnya dana internal perusahaan dan tidak mencukupi untuk mendanai kebutuhan perusahaan maka perusahaan akan meningkatkan hutangnya. Hutang yang tinggi, berdampak pada aset, laba, dan modal yang kecil. Maka dari itu, tingkat pengembalian aktiva akan mempengaruhi penahanan kas (Eugene \& Houston, 2006).

Teori dasar dari penelitian ini adalah Pecking Order Theory, yang mana menurut teori ini perusahaan lebih cenderung memilih sumber dana dari internal perusahaan berupa laba di tahan dari pada sumber dana eksternal seperti hutang agar dapat memenuhi struktur modalnya (Fahmi, 2012). Berdasarkan teori tersebut, peluang pertumbuhan perusahaan yang diperkirakan 
tinggi akan menpush perusahaan membuat kebijakan menahan kas dalam jumlah yang besar karena perusahaan yang memiliki peluang bertumbuh yang besar akan memerlukan kas yang tinggi untuk memenuhi kesempatan investasi berupa saham ataupun investasi pada aset tetap. Karena dengan jumlah kas yang tinggi tersebut perusahaan leluasa dalam memutarkan aset lancarnya. Begitu pula dengan rasio pengembalian aktiva, dimana rasio ini menunjukkan kemampuan perusahaan meningkatkan laba bersih dengan mengoptimalkan pengelolaan aktiva. Kaitannya dengan penahanan kas ialah, kas merupakan bagian dari aktiva yang sifatnya likuid maka untuk meningkatkan laba perusahaan membutuhkan aset yang likuid agar mudah digunakan dalam operasional. Dengan begitu, penahanan kas perusahaan akan ditingkatkan.

Berikut ini adalah data yang peneliti dapat dari laporan keuangan PT. Indocement Tunggal Prakarsa, Tbk selama periode 2008-2019 mengenai variabel-variabel yang akan diteliti oleh peneliti.

Tabel 1 Data Penelitian

\begin{tabular}{|c|c|c|c|}
\hline Periode & Peluang Pertumbuhan & Tingkat Pemgembalian Aktiva & Penahanan Kas \\
\hline 2009 & 8,13 & 20,68 & 19,76 \\
\hline 2010 & 5,3 & 21,01 & 30,52 \\
\hline 2011 & 24,69 & 19,84 & 37,81 \\
\hline 2012 & 24,49 & 20,93 & 46,02 \\
\hline 2013 & 8,1 & 18,83 & 47,33 \\
\hline 2014 & 6,98 & 18,25 & 38,96 \\
\hline 2015 & $-10,99$ & 15,76 & 31,31 \\
\hline 2016 & $-13,68$ & 12,83 & 32,08 \\
\hline 2017 & $-6,05$ & 6,44 & 28,73 \\
\hline 2018 & 5,25 & 4,12 & 26 \\
\hline
\end{tabular}

Sumber: Laporan Publikasi Keuangan PT.Indocement Tunggal Prakarsa, Tbk.

Pada data di atas dapat dilihat PT. Indocement Tunggal Prakarsa, Tbk terdapat beberapa masalah, pada tahun 2010 secara parsial peluang pertumbuhan mengalami penurunan namun tidak diikuti oleh penurunan penahan kas, kemudian tahun 2011 dan 2013 secara parsial rasio pengembalian aktiva mengalami penurunan namun penahanan kas justru meningkat. Lalu, tahun 2016 secara simultan, peluang pertumbuhan dan rasio pengembalian aktiva mengalami penurunan, namun penahanan kas justru mengalami kenaikan yang signfikan. Merujuk pada permasalahan di atas maka dipandang perlu melakukan penelitian terhadap PT. Indocement Tunggal Prakarsa, Tbk.

\section{Metode}

Artikel ini juga menggunakan metode deskriptif dan pendekatan kuantitatif, yakni untuk mendeskripsikan hasil penelitian yang datanya disajikan dalam bentuk numerik (Sugiyono, 2013). Data pada artikel ini merupakan data sekunder yang diambil dari laporan keuangan PT. Indocement Tunggal Prakarsa, Tbk. dan didukung dengan studi kepustakaan dan dokumentasi. Teknik analisis data diolah secara statistik dan kuantitatif menggunakan bantuan perangkat lunak SPSS. Teknik penghitungan yang digunakan adalah analisis regresi, uji hipotesis, dan uji kekuatan hubungan dengan R Square dan Pearson Product Moment 


\section{Hasil dan Pembahasan}

\subsection{Pengaruh Peluang Pertumbuhan terhadap Penahanan Kas}

Peluang pertumbuhan adalah keadaan perusahaan yang digambarkan dalam bentuk rasio sejauh mana perusahaan mampu bertahan dengan posisi ekonominya di tengah pertumbuhan perekonomian perusahaan dan sektor usahanya (Afiyan, 2018). Selain itu peluang pertumbuhan ini merupakan peluang investasi yang mungkin bisa dikembangkan oleh perusahaan. Menurut (Eugene \& Houston, 2006) perusahaan yang mempunyai peluang pertumbuhan yang tinggi harus memiliki kas yang cukup atau penahanan kas yang tinggi agar dapat digunakan dengan cepat dalam menindaklanjuti suatu peluang.

Penelitian ini ternyata tidak menjawab atau konsisten dengan teori di atas, berikut hasil penelitian yang telah di lakukan:

Tabel 1 Hasil Uji Regresi Linear dan Uji t Pengaruh Peluang Pertumbuhan terhadap Penahanan Kas

Coefficients ${ }^{\mathrm{a}}$

\begin{tabular}{|c|c|c|c|c|c|}
\hline \multirow[t]{2}{*}{ Model } & \multicolumn{2}{|c|}{ Unstandardized Coefficients } & Standardized & \multirow[t]{2}{*}{$\mathrm{t}$} & \multirow[t]{2}{*}{ Sig. } \\
\hline & B & Std. Error & Beta & & \\
\hline (Constant) & 32,302 & 2,835 & & 11,394 & ,000 \\
\hline $\begin{array}{cc}1 & \text { Peluang } \\
\text { Pertumbuhan }\end{array}$ & 297 & ,212 & ,444 & 1,400 & ,199 \\
\hline
\end{tabular}

a. Dependent Variable: Penahanan Kas

Sumber: output SPSS versi 20

Persamaan yang didapatkan dari hasil SPSS di atas adalah:

Penahanan Kas $=32,302+0,297$ Peluang Pertumbuhan

Didasarkan atas persamaan regresi tersebut, bisa dijelaskan apabila nilai $\mathrm{X}_{1}$ (Peluang Pertumbuhan) bernilai nol, maka Y (Penahanan Kas) bernilai 32,302. Sementara itu, jika $\mathrm{X}_{1}$ (Peluang Pertumbuhan) berubah sebesar 1 (satu) satuan, maka akan memberikan dampak pada peningkatan terhadap Y (Penahanan Kas) sebesar 0,297. Selanjutnya, persamaan regresi linear sederhana tersebut memperlihatkan bahwa Peluang Pertumbuhan memiliki arah pengaruh yang positif terhadap Penahanan Kas.

Pengaruh Peluang Pertumbuhan terhadap Penahanan Kas dapat dilihat dari hasil uji $t$ dimana hasil di atas tidak memenuhi kriteria berpengaruh karena 1,400<2,306 dengan Sig. 0,199>0,05. Sehingga peneliti mendapatkan hasil akhir bahwa Peluang Pertumbuhan tidak memiliki pengaruh terhadap Penahanan Kas PT. Indocement Tunggal Prakarsa, Tbk. periode 2009-2018.

Selanjutnya kekuatan hubungan dan kontribusi pengaruh Peluang Pertumbuhan terhadap Penahanan Kas dapat dilihat pada tabel berikut:

\section{Tabel 2 Hasil Uji Korelasi dan Koefisien Determinasi}

Model Summary

\begin{tabular}{|c|c|c|c|c|}
\hline Model & $\mathrm{R}$ & $\mathrm{R}$ Square & Adjusted R Square & Std. Error of the Estimate \\
\hline 1 &, $444^{\mathrm{a}}$ &, 197 &, 096 & 8,25405 \\
\hline
\end{tabular}

a. Predictors: (Constant), Peluang Pertumbuhan

Sumber: hasil output SPSS versi 20 
Berdasarkan perhitungan SPSS di atas dapat diketahui besarnya hubungan Peluang Pertumbuhan terhadap Penahanan Kas adalah 0,444 korelasi tersebut sedang. Dan R Square $\left(\mathrm{r}^{2}\right)$ 0,154 atau sama dengan 19,7\%. Artinya, Penahanan Kas hanya 19,7\% dipengaruhi oleh fluktuasi Peluang Pertumbuhan, sedangkan sisanya 80,3\% Penahanan Kas dipengaruhi oleh faktor lain.

Berdasarkan hasil penelitian diatas growth opportunity memiliki pengaruh yang positif namun tidak signifikan. Seperti yang telah diuraikan sebelumnya perusahaan yang berpeluang untuk mencapai pertumbuhan perusahaan yang tinggi akan mendorong perusahaan untuk terus melakukan ekspansi sehingga akan menahan kas dalam jumlah yang banyak agar dapat membiayai investasi mendatang tersebut. Namun pada kenyataannya PT. Indocement Tunggal Perkasa, Tbk. saat ini belum menentukan langkah ekspansi bisnis untuk beberapa tahun kedepan hal ini sesuai dengan artikel yang berjudul Indocement (INTP) masib fokus menyelesaikan Agenda Ekspansi Terkini. Pada tahun 2018 sampai 2019 PT. Indocement Tunggal Perkasa, Tbk. sudah mengeluarkan dana yang besar dalam ekspansi bisnis tambang batu, sehingga pihak manajemen perusahaan tahun depan tidak akan melakukan ekspansi lagi. Maka dari itu, perusahaan tidak terlalu membutuhkan cash holding yang tinggi untuk mendanai internal perusahaannya.

Hasil penelitian ini konsisten dengan penelitian yang dilakukan oleh (Maulana, 2018) dan (Afiyan, 2018) yang menghasilkan bahwa peluang pertumbuhan tidak berpengaruh terhadap penahanan kas. Namun bertolak belakang dengan penelitian (Zulhilmi, 2015) dan (Saputra, 2018) yang hasil penelitiannya peluang pertumbuhan berpengaruh signfikan terhadap penahanan kas.

\subsection{Pengaruh Rasio Pengembalian Aktiva terhadap Penahanan Kas}

Rasio Pengembalian Aktiva merupakan rasio keuangan yang menunjukkan kemampuan aset dalam menghasilkan laba bersih. Menurut (Hery, 2015) semakin tinggi tingkat pengembalian aktiva mengindikasikan semain besar laba bersih yang didapatkan dari satu rupiah modal yang terdapat dalam total aset. Pun sebaliknya, ketika tingkat pengembalian aktiva rendah maka laba bersih yang ada pun juga rendah.

Merujuk pada teori di atas, tenyata pada penelitian ini rasio pengembalian aktiva tidak memiliki pengaruh terhadap terhadap Penahanan Kas PT. Indocement Tunggal Prakarsa, Tbk. periode 2009-2018. Hasil penelitiannya adalah:

Tabel 3 Hasil Uji Regresi Linear dan Uji $t$ Pengaruh Rasio Pengembalian Aktiva terhadap Penahanan Kas

Coefficients ${ }^{\mathrm{a}}$

\begin{tabular}{|c|c|c|c|c|c|}
\hline \multirow{2}{*}{ Model } & \multicolumn{2}{|c|}{$\begin{array}{c}\text { Unstandardized } \\
\text { Coefficients }\end{array}$} & $\begin{array}{c}\text { Standardized } \\
\text { Coefficients }\end{array}$ & \multirow{2}{*}{ S ig. } \\
\cline { 2 - 4 } & $\mathrm{B}$ & $\begin{array}{c}\text { Std. } \\
\text { Error }\end{array}$ & Beta & \\
\hline \multirow{2}{*}{$\begin{array}{c}\text { (Constant) } \\
\text { Rasio } \\
\text { Pengembalian } \\
\text { Aktiva }\end{array}$} & 24,995 & 7,739 & & 3,230 &, 012 \\
&, 558 &, 458 &, 396 & 1,220 &, 257 \\
\hline
\end{tabular}

a.Dependent Variable: Penahanan Kas

Sumber: hasil output SPSS versi 20 
Berdasarkan tabel di atas diperoleh persamaan:

Penahanan Kas $=24,995+0,558$ Rasio Pengembalian Aktiva

Didasarkan atas persamaan regresi tersebut, bisa dijelaskan apabila nilai $\mathrm{X}_{2}$ (Rasio Pengembalian Aktiva) bernilai nol, maka Y (Penahanan Kas) bernilai 24,995. Sementara itu, jika $\mathrm{X}_{2}$ (Rasio Pengembalian Aktiva) berubah sebesar 1 (satu) satuan, maka akan memberikan dampak pada peningkatan terhadap Y (Penahanan Kas) sebesar 0,558. Selanjutnya, persamaan regresi linear sederhana tersebut memperlihatkan bahwa Rasio Pengembalian Aktiva berpengaruh positif terhadap Penahanan Kas.

Pengaruh Rasio Pengembalian Aktiva dalam mempengaruhi kenaikan dan penurunan Penahanan Kas dapat dilihat dari hasil uji $t$. Dari tabel di atas interpretasinya adalah $t$ tabel sebesar 1,220 dengan signifikansi 0,257. Hal ini memenuhi syarat thitung $<t_{\text {tabel }}(1,220<2,306)$ dengan nilai taraf signifikansi sebesar 5\%. Hasil tersebut berarti Rasio Pengembalian Aktiva tidak memiliki pengaruh yang signifikan terhadap Penahanan Kas.

Selanjutnya kekuatan hubungan dan kontribusi pengaruh Rasio Pengembalian Aktiva terhadap Penahanan Kas dapat dilihat pada tabel berikut:

\section{Tabel 4 Hasil Uji Korelasi dan Koefisien Determinasi}

Model Summary

\begin{tabular}{|c|c|c|c|c|}
\hline Model & $\mathrm{R}$ & R Square & Adjusted R Square & Std. Error of the Estimate \\
\hline 1 &, $396^{\mathrm{a}}$ &, 157 &, 051 & 8,45754 \\
\hline
\end{tabular}

a.Predictors: (Constant), Rasio Pengembalian Aktiva

Sumber: output SPSS versi 20

Berdasarkan perhitungan SPSS di atas dapat diketahui besarnya hubungan Rasio Pengembalian Aktiva terhadap Penahanan Kas adalah 0,396 dimana berada pada kriteria lemah. Dan R Square $\left(\mathrm{r}^{2}\right)$ menunjukkan nilai koefisien determinasi, besarnya $\mathrm{r}^{2}$ adalah 0, 157 atau sama dengan 15,7\%. Hal ini berarti Rasio Pengembalian Aktiva mampu menjelaskan pengaruhnya terhadap Penahanan Kas hanya 15,7\% kemudian sisanya sebesar 84,3\% dipengaruhi oleh faktor lain.

Dalam penelitian ini Return On Asset (ROA) memiliki pengaruh positif namun tidak berpengaruh signifikan terhadap cash holding. Berdasarkan artikel yang berjudul Indocement 100\% Laba Jadi Dividen, Investor Dapat Rp 550/ unit diperoleh informasi bahwa manajemen perusahaan memutuskan untuk membagikan seluruh laba bersih dan laba ditahan dalam bentuk dividen kepada para pemegang saham. Hal ini, mengakibatkan tidak adanya penahanan kas berupa uang tunai yang digunakan untuk kepentingan internal perusahaan dan lebih memilih menggunakan cash holding yang ada untuk membagikannya kepada pemegang saham. Penulis berasumsi, PT. Indocement Tunggal Prakarsa, Tbk. lebih mementingkan kepuasan investor agar investor terus menanamkan sahamnya diperusahaan tersebut, dengan demikian kegiatan operasional perusahaan akan tertutupi kembali dengan investasi yang diberikan oleh investor.

Hasil penelitian ini tidak mendukung penelitian sebelumnya yang dilakukan oleh (Angelia \& Dwimulyani, 2019) yang mana hasil penelitian secara parsial cash holding dipengaruhi oleh profitability. Namun mendukung hasil penelitian (Sudarmi \& Nur, 2018) bahwa Retur On Asset berpengaruh negatif dan signifikan terhadap cash holding. 


\subsection{Pengaruh Peluang Pertumbuhan dan Rasio Pengembalian Aktiva terhadap Penahanan Kas}

Penahanan Kas dijelaskan sebagai aset lancar perusahaan yang sangat likuid yang kemudian dipegang perusahaan untuk siap diinvestasikan kembali dalam bentuk aset tetap dan saham, kemudian dibagikan dalam bentuk dividen atau menyimpannya untuk keperluan perusahaan, hal ini sesuai kebijakan yang dikeluarkan oleh manajer. Keberadaan penahanan kas ini dapat menjadi fungsi penjagaan yang dapat digunakan pada suatu waktu (Wenny, 2017).

Sesuai yang telah dijelaskan di atas, peluang pertumbuhan yang tinggi pada perusahaan akan memerlukan kecukupan kas yang tinggi agar siap sedia digunakan saat ada peluang di depan mata. Sedangkan rasio pengembalian aktiva berhubungan dengan pengelolaan aset yang efisien sehingga menghasilkan laba yang tinggi. Maka, apabila peluang pertumbuhan tinggi, kas yang ada dapat digunakan untuk menambah aset. Kemudian aset tersebut dikelola dengan baik sehingga menghasilkan laba bersih yang tinggi yang akan berimplikasi pada pembagian dimana ada yang dibagikan kepada pemegang saham dalam bentuk dividen tunai, atau penahanan kas yang akan diinvestasikan kembali.

Berikut hasil penelitian yang didapatkan dari pengolahan data menggunakan SPSS:

Tabel 5 Hasil Uji F

ANOVA

\begin{tabular}{|c|c|c|c|c|c|c|}
\hline \multicolumn{1}{|c|}{ Model } & Sum of Squares & $\mathrm{df}$ & Mean Square & F & Sig. \\
\hline \multirow{3}{*}{1} & Regression & 160,036 & 2 & 80,018 & 1,080 &, $390^{\mathrm{b}}$ \\
& Residual & 518,616 & 7 & 74,088 & & \\
& Total & $\mathbf{6 7 8 , 6 5 1}$ & 9 & & & \\
\hline
\end{tabular}

a. Dependent Variable: Penahanan Kas

b. Predictors: (Constant), Peluang Pertumbuhan, Rasio Pengembalian Aktiva Sumber: output hasil SPSS versi 20.0

Tabel di atas merupakan hasil uji hipotesis secara simultan, F hitung yang didapatkan adalah 1,080 dengan Sig 0,390. Ini tidak memenuhi kriteria berpengaruh, karena 1,080<4,74 dan $0,390>0,05$. Sehingga, disimpulkan secara simultan variabel peluang pertumbuhan dan rasio pengembalian aktiva tidak dapat mempengaruhi perubahan penahanan kas pada PT. Indocement Tunggal Prakarsa, Tbk. periode 2009-2018.

Selanjutnya kekuatan hubungan dan kontribusi pengaruh peluang pertumbuhan dan rasio pengembalian aktiva terhadap penahanan kas dapat dilihat pada tabel berikut:

Tabel 4 Hasil Uji Korelasi dan Koefisien Determinasi

Model Summary ${ }^{\mathrm{b}}$

\begin{tabular}{|c|c|c|c|c|}
\hline Model & $\mathrm{R}$ & $\mathrm{R}$ Square & $\begin{array}{c}\text { Adjusted R } \\
\text { Square }\end{array}$ & Std. Error of the Estimate \\
\hline 1 &, $486^{\mathrm{a}}$ &, 236 &, 017 & 8,60744 \\
\hline
\end{tabular}

a. Predictors: (Constant), Peluang Pertumbuhan, Rasio Pengembalian Aktiva

b. Dependent Variable: Penahanan Kas

Sumber: output hasil SPSS versi 20.0

Berdasarkan perhitungan SPSS di atas dapat diketahui besarnya hubungan Peluang Pertumbuhan dan Rasio Pengembalian Aktiva terhadap Penahanan Kas adalah 0,486 berada 
pada interval 0,40,499 yang berarti korelasi tersebut sedang. Sedangkan, koefisien determinasi memiliki nilai 0,236 yang artinya terdapat hubungan antara Peluang Pertumbuhan dan Rasio Pengembalian Aktiva terhadap Penahanan Kas sebesar 23,6\% sedangkan 74,4\% dipengaruhi oleh variabel lain yang tidak diteliti dalam penelitian ini.

Cash holding merupakan kas yang dimiliki perusahaan. Cash holding dapat digunakan dalam kegiatan operasi maupun membayar kewajiban perusahaan. Cash holding dapat dipengaruhi oleh cash flow, growth opportunity, leverage, profitability, cash conversion cycle. Growth opportunity dan Return On Asset (ROA) berkaitan dengan teori cash holding dalam pecking order theory, menurut teori ini sumber dana dari dalam berupa laba ditahan cenderung dipilih oleh perusahaan dari pada sumber dana dari luar berupa utang untuk memenuhi struktur modalnya. Struktur modal bertujuan memadukan sumber dana permanen yang selanjutnya digunakan perusahaan dengan cara yang diharapkan akan mampu memaksimumkan niai perusahaan. Namun teori tersebut tidak sesuai dengan keadaan yang terjadi pada PT. Indocement Tunggal Prakarsa, Tbk. Berdasarkan hasil perhitungan diperoleh hasil tidak terdapat pengaruh signifikan peluang pertumbuhan dan rasio pengembalian aktiva terhadap penahanan kas secara simultan.

Seperti yang sudah dijelaskan pada pembahasan nomor satu dan dua, bahwa rasio pengembalian aktiva memiliki pengaruh yang tidak signifikan karena rasio pengembalian aktiva yang ada pada PT. Indocement Tunggal Prakarsa digunakan untuk membagikan dividen kepada para pemegang saham. Hal tersebut dilakukan karena PT. Indocement Tunggal Prakarsa, Tbk. tidak memiliki rencana ekspansi bisnis. Maka dari itu, berdasarkan packing order theory yang dihubungkan dengan kas, yang menyatakan bahwa kas adalah penyangga antara laba ditahan dan kebutuhan investasi dimana apabila kebutuhan investasi meningkat maka akan memaksimalkan laba ditahan berupa cash holding untuk membiayai peluang pertumbuhan atau investasi mendatang tidak berlaku untuk penelitian ini. Karena seluruh laba bersih dan laba ditahan perusahaan dibagikan dalam bentuk dividen kepada para pemegang saham sehingga tidak ada cash holding.

\section{Kesimpulan}

Penelitian ini menghasilkan kesimpulan berupa peluang pertumbuhan tidak mempengaruhi secara signifikan kebijakan penahanan kas PT. Indocement Tunggal Prakarsa, Tbk. dimana proporsi pengaruhnya hanya 19,7\%. Kemudian, rasio pengembalian aktiva juga tidak memberikan pengaruh yang signifikan terhadap kebijakan penahanan kas PT. Indocement Tunggal Prakarsa, Tbk. dimana proporsi pengaruhnya hanya 15,7\%. Dan terakhir, kedua faktor tersebut secara bersamaan juga tidak mampu memberikan pengaruh signifikan terhadap kebijakan penahanan kas PT. Indocement Tunggal Prakarsa, Tbk. dimana proporsi pengaruhnya hanya $23,6 \%$, artinya sebesar $76,4 \%$ terdapat faktor lain yang mempengaruhi dan pengaruhnya lebih kuat. Implikasi dari penelitian ini adalah PT. Indocement Tunggal Prakarsa, Tbk. dalam melakukan penahanan kas harus memperhatikan faktor lain karena jika kas yang tersedia tidak cukup akan mengganggu operasional perusahaan.

\section{Referensi}

Afiyan, I. (2018). Pengaruh Struktur Aktiva, Growth Opportunity, Risiko dan Umur Perusahaan Terhadap Struktur Modal Bank Syariah. Jakarta: Repository UIN Syarief Hidayatullah. 
Angelia, M., \& Dwimulyani, S. (2019). Profitability, Leverage, dan Firm Size Mempengaruhi Cash Holding dengan Tax Avoidance sebagai Variabel Intervening. Prosiding Seminar Nasional Pakar ke 2 , (pp. 2.46 .1 - 2. 46. 11).

Eugene, B. F., \& Houston, J. F. (2006). Dasar-dasar Manajemen Keuangan . Jakarta: Salemba Empat.

Fahmi, I. (2012). Pengantar Manajemen Keuangann. Bandung: Alfabeta.

Hery. (2015). Analisis Laporan Keuangan (Pendekatan Rasio Keuangan). Yogyakarta: Publishing Service.

Jinkar, R. T. (2013). Analisis Faktor-faktor Penentu Kebijakan Cash Holding Perusahaan Manufaktur di Indonesia. Depok: Perpustakaan Digital Universitas Indonesia.

Maulana, I. (2018). Pengaruh Cash Conversion Cycle, Net Working Capital, dan Growth Opportunity terhadap Cash Holding pada Perusahaan Properti dan Real Estate yang Terdaftar pada Bursa Efek Indonesia. Banda Aceh: Universitas Syiah Kuala .

Saputra, Y. (2018). Analisis Pengaruh Growth Opportunity, NWC, Cash Flow, dan DPR terhadap Cash Holding pada Perusahaan Manufaktur yang Terdaftar di Bursa Efek Indonesia. Yogyakarta: Universitas Muhammadiyah .

Simanjuntak, S. F., \& Wahyudi, A. S. (2017). Faktor-Faktor yang Mempengaruhi Cash Holding Perusahaan. Jurnal Bisnis dan Akuntansi Volume 19 Nomor 1.

Sudarmi, E., \& Nur, T. (2018). Analisis Faktor-faktor yang Mempengaruhi Cash Holdings pada Perusahaan Manufaktur yang Tercatat di Bursa Efek Indonesia. ESENSI, Vol. 21 No. 1, 14-33.

Sugiyono. (2013). Metode Penelitian Kuantitatif Kualitatif dan R\&D . Bandung: Alfabeta.

Wenny, S. M. (2017). Analisis Faktor-faktor yang Mempengarubi Cash Holding Pada Perusahaan Manufaktur yang Terdaftar di Bursa Efek Indonesia tabun 2013-2015. Bandar Lampung: Universitas Lampung.

Zulhilmi, A. (2015). Pengaruh Growth Opportunity, Cash Conversion Cycle dan Leverage terhadap Cash Holding, Net Working Capital Perusahaan. Jurnal Ekonomi Pembangunan Vol. 5, No.1. 